\title{
Quality of life among people living with acquired immune deficiency syndrome receiving anti-retroviral therapy: a study from Nepal
}

This article was published in the following Dove Press journal:

HIVIAIDS - Research and Palliative Care

25 September 2013

Number of times this article has been viewed

\section{Smith Giri \\ Maniraj Neupane \\ Sushil Pant \\ Utsav Timalsina \\ Sagar Koirala \\ Santosh Timalsina \\ Sashi Sharma}

Department of Medicine, Tribhuvan University Teaching Hospital,

Kathmandu, Nepal
Correspondence: Smith Giri Department of Medicine, Tribhuvan University Teaching Hospital, Maharajgunj, PO Box 1524, Kathmandu, Nepal Tel +977 0l 44I09II

Fax+977 0I 4422553

Email smithgiri963@gmail.com
Purpose: The present study was undertaken to determine the impact of acquired immune deficiency syndrome (AIDS) on the quality of life of affected individuals in Nepal.

Patients and methods: A cross sectional study was done among 70 individuals attending the Anti-Retroviral Therapy clinic of the University Hospital in Nepal. Quality of life (QOL) was evaluated using World Health Organization Quality of life questionnaire (WHO QOL-BREF) instrument. Statistical analysis was done using SPSS Version 17.0.

Results: The median scores with interquartile range (IQR) in four domains of QOL in descending order were physical (61; IQR 22), social (58; IQR 33), environmental (56; IQR 13), and psychological (54; IQR 8). Older age was associated with lower perceived overall QOL. Females were more likely to have lower QOL scores in the social and psychological domains. Higher CD4 counts and a married status were significant predictors of higher QOL scores in the environmental domain.

Conclusion: Being older, female, single, and having advanced clinical stage is associated with lower QOL scores in people living with AIDS. Lowest QOL scores were seen in the psychological domain suggesting the need of psychological interventions.

Keywords: quality of life, AIDS, Nepal, WHO QOL-BREF

\section{Introduction}

The global pandemic of human immunodeficiency virus/acquired immune deficiency syndrome (HIV/AIDS) has caused millions of deaths worldwide and has crippled the lives of many more. In 2011, an estimated 34 million individuals were living with HIV and 1.7 million died from AIDS related causes worldwide. ${ }^{1}$ Developing nations such as Nepal are no exception. HIV was first reported in Nepal in 1988; by the year 2011, the number of individuals with HIV is estimated to be about 50, 287. 2,3

The introduction of highly active antiretroviral therapy (HAART) has led to a marked reduction in AIDS-related morbidity and mortality. ${ }^{4}$ People living with HIV/ AIDS often suffer from intense social stigma which forces an individual to change jobs or places of living, putting further stress on the already weak economic situation. ${ }^{5}$ They might experience discrimination or misunderstanding, tend to become isolated and lose social support from persons significant to them. ${ }^{6}$ This often compromises the quality of life (QOL) of such individuals.

QOL is a multi-dimensional concept of which definition remains controversial. ${ }^{5}$ It is conceptualized in terms of an absence of pain or an ability to function in day to day life. ${ }^{7}$ Further, as health is generally cited as one of the most important determinants 
of overall quality of life, it has been suggested that QOL may be uniquely affected by specific disease processes such as AIDS. ${ }^{5}$

One of the aims of HIV/AIDS therapy should be improving the quality of life of affected people. Studies on QOL in individuals with AIDS elsewhere have shown that sex, ${ }^{8-10}$ age group, ${ }^{11} \mathrm{CD} 4$ counts, ${ }^{8,11-13}$ marital status, ${ }^{14,15}$ educational status, ${ }^{15-18}$ and the status of employment ${ }^{5}$ have a significant impact on their QOL. However, the QOL of people living with AIDS is largely unknown in Nepal; few studies have been done to analyze the QOL in this population., ${ }^{2,19}$ These studies have not identified the socio-demographic and clinical predictors of a poorer QOL among individuals living with AIDS. It thus follows that studies are needed to understand the status of quality of life of people living with AIDS and to understand the various factors that determine it. Identification of these factors will allow appropriate intervention measures to be taken to improve QOL in this population.

The objective of this study was to identify the QOL in people living with AIDS and to examine relationships between QOL and socio-demographic characteristics and clinical status of such individuals.

\section{Material and methods}

This was a cross sectional study done among 70 consecutive sample of individuals attending the outpatient Anti-Retroviral Therapy (ART) Clinic of Tribhuvan University Teaching Hospital (TUTH), Kathmandu, Nepal from November 2010 to March 2011. Ethical clearance was obtained from the Institutional Review Board of the Institute of Medicine before conducting the study. Pertinent demographic and clinical information including age, sex, employment, educational, and marital status, perceived social support and CD4 count was gathered using a structured questionnaire and QOL was measured with the World Health Organization Quality of life questionnaire (WHO QOL-BREF) instrument. ${ }^{20} \mathrm{WHO}$ QOL-BREF is a shortened version of the WHO QOL instrument consisting of a 26 item questionnaire that is comparable across different languages and cultures. ${ }^{20}$ WHO QOL-BREF has been well validated for measuring quality of life in people living with AIDS across different settings ${ }^{21-23}$ and has been

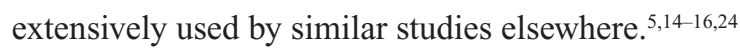

Individuals with AIDS for $>18$ years regularly attending the ART clinic of TUTH with no severe life events in the past 6 months (such as loss of a spouse or of children) were included in the study. We decided to include individuals without any cognitive impairment (at least a score of 10-12 on the Mini Mental State Examination), as the study questionnaire was self-reported and required some degree of alertness to respond appropriately. Terminally ill and newly diagnosed people with AIDS as well as those not on regular follow-up were excluded from the study.

For the purpose of this study, the English version of WHO-QOL BREF was translated into Nepalese language as per the Brislin's model of translation. ${ }^{25}$ It constituted of forward translation of the English version of the questionnaire into Nepalese by a bilingual health professional. Then, the translated questionnaire was reviewed by a monolingual Nepalese layperson. Subsequently, it was back translated to English by another bilingual physician who was blinded to the original English version. Finally, the researcher checked the back-translated version and the original version for linguistic congruence and cultural relevancy. Any error in translation had to go through the entire process over again until maximum similarity was obtained between the two questionnaires. The final approved version of the questionnaire was pretested on 10 people living with HIV/AIDS before preparing the final version of the questionnaire. No major changes were made in the questionnaire except for rephrasing some ambiguous words. The pretested patients were excluded from the final data analysis.

WHO QOL-BREF has 26 items grouped under four domains: (i) physical health, (ii) psychological well-being, (iii) social relations, and (iv) environment. Each item is categorized into a five point Likert scale. The items under the domains are summarized in Table 1. There are two other items that are measured separately: (1) patient's overall perception of QOL, and (2) overall perception on his/her health. Domain scores are scaled in a positive direction; higher scores denote higher QOL. The mean score of items within each domain is used to calculate the domain scores compatible with the scores used in WHO QOL-100 and subsequently transformed to a $0-100$ scale. ${ }^{20}$

Written informed consent was obtained from all participants after explaining the nature and purpose of the study in detail. Basic demographic and clinical information as mentioned above was collected by three study investigators. The QOL questionnaire was completed by participants themselves if they could read and write. However, for illiterate patients, questionnaires were completed by an investigator after providing detailed explanations of the statements as well as the options and noting their responses.

Data was analyzed using SPSS version 17.0 (IBM Corporation, Armonk, NY, USA). Descriptive variables such as mean, median, and standard deviation (SD) were calculated as the primary method of data analysis. Normality of the dis- 
Table I Summary of the components of different domains in WHO QOL-BREF Instrument

\begin{tabular}{|c|c|}
\hline Domain & Components \\
\hline I. Physical health & $\begin{array}{l}\text { - Activities of daily living } \\
\text { - Dependence on medicinal substances } \\
\text { and medicinal aids } \\
\text { - Energy and fatigue } \\
\text { - Pain and discomfort } \\
\text { - Sleep and rest } \\
\text { - Work capacity }\end{array}$ \\
\hline 2. Psychological health & $\begin{array}{l}\text { - Bodily image and appearance } \\
\text { - Negative feelings } \\
\text { - Positive feelings } \\
\text { - Self-esteem } \\
\text { - Spirituality/Religion/Personal beliefs } \\
\text { - Thinking, learning, memory and } \\
\text { concentration }\end{array}$ \\
\hline 3. Social relationships & $\begin{array}{l}\text { - Personal relationships } \\
\text { - Social support } \\
\text { - Sexual activity }\end{array}$ \\
\hline 4. Environment & $\begin{array}{l}\text { - Financial resources } \\
\text { - Freedom, physical safety and security } \\
\text { - Health and social care: accessibility and } \\
\text { quality } \\
\text { - Home environment } \\
\text { - Opportunities for acquiring new } \\
\text { information and skills } \\
\text { - Participation in and opportunities for } \\
\text { recreation/leisure activities } \\
\text { - Physical environment (pollution/noise/ } \\
\text { traffic/climate) } \\
\text { - Transport }\end{array}$ \\
\hline
\end{tabular}

Abbreviation: WHO QOL-BREF, World Health Organization Quality of life questionnaire.

tribution of the data was ascertained using the Shapiro-Wilk test. Cronbach's $\alpha$ and inter-domain correlation coefficients were calculated to test the reliability and validity of the Nepalese version of WHO QOL-BREF. Inter-domain correlation coefficients between the various domain scores and the overall QOL score were calculated using Pearson's alpha or Spearman's rho depending on the normality of distribution. The internal consistency reliability scale was examined using Cronbach's $\alpha$, where a value of 0.7 or above was considered to indicate good consistency. ${ }^{26}$ The difference between the QOL scores between and among the different demographic and clinical variables was calculated using Analysis of Variance (ANOVA) or Mann-Whitney $U$ test and Kruskal-Wallis test depending on the normality of the data. The level of significance chosen was $5 \%$.

\section{Results}

The mean age of the study population was 38.9 years (range 21-60 years, SD 8.8 years). The male to female ratio was 1.9:1. Most respondents were married $(77 \% ; n=54)$, while
Table 2 Demographic characteristics of the study participants

\begin{tabular}{|c|c|}
\hline & Frequency (percentage) \\
\hline \multicolumn{2}{|c|}{ Age group in years* } \\
\hline$<25$ & $2(2.9)$ \\
\hline $25-30$ & $6(8.6)$ \\
\hline $30-35$ & $22(31.4)$ \\
\hline $35-40$ & $16(22.9)$ \\
\hline$>40$ & $24(34.3)$ \\
\hline \multicolumn{2}{|l|}{ Sex } \\
\hline Male & $46(65.7)$ \\
\hline Female & $24(34.3)$ \\
\hline \multicolumn{2}{|c|}{ Level of education } \\
\hline Illiterate & $26(37.1)$ \\
\hline Primary & $22(3 \mid .5)$ \\
\hline Secondary & $10(14.3)$ \\
\hline High school & $8(I I .4)$ \\
\hline University & $4(5.7)$ \\
\hline \multicolumn{2}{|c|}{ Employment status } \\
\hline Employed & $32(45.7)$ \\
\hline Unemployed & $38(54.3)$ \\
\hline \multicolumn{2}{|l|}{ Marital status } \\
\hline Single & $6(8.6)$ \\
\hline Married & $54(77.1)$ \\
\hline Separated & $2(2.9)$ \\
\hline Widowed & $8(8.6)$ \\
\hline \multicolumn{2}{|l|}{ Social support } \\
\hline Yes & $54(77.1)$ \\
\hline No & $16(22.9)$ \\
\hline \multicolumn{2}{|l|}{ CD4 count ${ }^{\#}$} \\
\hline$<200$ & $16(22.9)$ \\
\hline $200-500$ & $48(68.6)$ \\
\hline$>500$ & $6(8.6)$ \\
\hline
\end{tabular}

Notes: *Mean age 38.9 , standard deviation 8.79 , range 21-60 years; ${ }^{*}$ mean CD4 count $301 / \mathrm{mm}^{3}$, standard deviation, 130, range $75-687 / \mathrm{mm}^{3}$.

$8 \%(\mathrm{n}=6)$ were single. Most patients were illiterate $(37 \%$; $\mathrm{n}=26)$ and about a third $(\mathrm{n}=22)$ received only primary education. Fifty-four percent $(\mathrm{n}=38)$ of the respondents were unemployed and about $77 \%$ (54) admitted to having received adequate social support. The demographic characteristics of the study population have been summarized in Table 2. Majority of the patients $(68 \% ; n=48)$ had a CD4 Count between 200-500.

The QOL scores in all domains had skewed distributions ( $P$-values in the Shapiro-Wilk test were $>0.05$ in all cases). Therefore, non-parametric tests were used for all kinds of analyses on QOL scores. The median score was highest for the physical domain (61; 1 st quartile 46, 3rd quartile 68), followed by social domain (58; 1 st quartile 42 and 3 rd quartile 75 ), environmental domain (56; 1 st quartile 50 and 3 rd quartile 63 ), and psychological domain (54; 1 st quartile 50 and 3 rd quartile 58 ; Table 3 ). The internal consistency among the four domains was acceptable (Cronbach's $\alpha 0.71)$. The QOL scores of all four domains were positively 
Table 3 Median scores (SD) of different domains of the quality of life and their correlation with overall QOL

\begin{tabular}{llll}
\hline QOL domain & $\begin{array}{l}\text { Median } \\
\text { score (SD) }\end{array}$ & $\begin{array}{l}\text { Score } \\
\text { range }\end{array}$ & $\begin{array}{l}\text { Correlation with } \\
\text { overall QOL }\end{array}$ \\
\hline Overall QOL & $4(0.76)$ & $\mathrm{I}-5$ & \\
Physical & $61(14.9)$ & $32-93$ & 0.40 \\
Psychological & $54(12.7)$ & $38-100$ & 0.55 \\
Social & $58(18.7)$ & $25-92$ & 0.40 \\
Environmental & $56(8.83)$ & $28-78$ & 0.16 \\
\hline
\end{tabular}

Abbreviations: $\mathrm{QOL}$, quality of life; SD, standard deviation.

correlated with the total measure of the quality of life (Spearman's rho ranging from 0.16 to 0.55 ). The strongest correlation was seen in the psychological domain (Spearman's rho $0.55)$ as shown in Table 3.

The median QOL domain scores and their standard deviations based on the various demographic and clinical variables have been summarized in Table 4 . Bivariate analyses were done using the appropriate non-parametric tests (Mann-Whitney $U$ test or Kruskal-Wallis test with post hoc analysis). Older age (age $>35$ years versus $<35$ years) was associated with a significantly lower perceived overall QOL score (median score 3 versus 4, Mann-Whitney $U$ statistic $350, z$ value $-3.3, P$-value 0.001$)$. Also, females had significantly lower QOL scores than males in psychological domain (median score 54 versus 58, Mann-Whitney $U$ statistic $358, z$ value $-2.44, P$-value 0.015 ) and social domain (median score 51 versus 67, Mann-Whitney $U$ statistic 3.75, $z$ value $-2.2, P$-value 0.03 ).

A statistically significant difference was seen among the various clinical categories of patients and environmental domain scores (Kruskal-Wallis chi-square 10.5, degrees of freedom 2, $P$-value 0.005$)$. Using post-hoc analysis, the greatest difference was ascertained to be between CD4 category $200-500$ cells $/ \mathrm{mm}^{3}$ and category $>500$ cells/ $\mathrm{mm}^{3}$ (chi-square 9.2). Similarly, a significant difference was observed in the environmental domain score based on the marital status of an individual (married versus single/ widowed/separated; median score 56 versus 48.5, MannWhitney $U$ statistic $136, z$ value $-2.8, P$-value 0.001 ). However, the level of education, employment status, and

Table 4 Comparison of the median \pm SD scores of HIV/AIDS domains of the quality of life based on demographic variables

\begin{tabular}{|c|c|c|c|c|c|}
\hline \multirow[t]{2}{*}{ Variable } & \multicolumn{5}{|c|}{ WHO QOL-BREF domain scores and standard deviations } \\
\hline & Physical & Psychologic & Social & Environmental & Overall QOL \\
\hline \multicolumn{6}{|l|}{ Age in years } \\
\hline$<35$ & $61(15.2)$ & $58(13.8)$ & $67(19.1)$ & $56(5.7)$ & $4(0.4)$ \\
\hline$>35$ & $57(14.4)$ & $54(12.0)$ & $54.5(18.5)$ & $56(10.7)$ & $3(0.9)$ \\
\hline \multicolumn{6}{|l|}{ Sex } \\
\hline Male & $62(15.4)$ & $58(\mid 4.1)$ & $67(19.0)$ & $56(8.6)$ & $4(0.7)$ \\
\hline Female & $53(12.9)$ & $54(7.6)$ & $51(16.5)$ & $56(9.5)$ & $4(0.9)$ \\
\hline \multicolumn{6}{|c|}{ Employment status } \\
\hline Employed & $58.5(16.3)$ & $56(13.6)$ & $57(20.4)$ & $56(6.8)$ & $4(0.9)$ \\
\hline Unemployed & $62(13.8)$ & $54(12.1)$ & $67(17.4)$ & $56(10.2)$ & $4(0.7)$ \\
\hline \multicolumn{6}{|l|}{ Social support } \\
\hline Yes & $61(15.9)$ & $58(13.9)$ & $58(20.5)$ & $56(9.4)$ & $4(0.7)$ \\
\hline No & $53(11.2)$ & $54(6.4)$ & 57 (II.6) & $56(6.7)$ & $3.5(1)$ \\
\hline \multicolumn{6}{|l|}{ Marital status } \\
\hline Single & $62(15.7)$ & $67(8.8)$ & 75 (18.9) & $53(4.1)$ & $4(0.5)$ \\
\hline Married & 61 (I5.5) & $58(\mid 4 . I)$ & $58(19.2)$ & $56(9.0)$ & $4(0.7)$ \\
\hline Separated & $34(2.8)$ & $54(0)$ & $46(5.7)$ & $64.5(2.1)$ & $4(0.2)$ \\
\hline Widowed & $60(7.5)$ & $54(1.9)$ & 47 (II.7) & $47(2.3)$ & $3.5(1.3)$ \\
\hline \multicolumn{6}{|l|}{ Education } \\
\hline Illiterate & $64(14.1)$ & $58(13.0)$ & $58(17.3)$ & $56(8.9)$ & $4(0.6)$ \\
\hline Primary & $61(12.6)$ & $54(7.6)$ & $58(13.8)$ & $56(4.4)$ & $4(0.9)$ \\
\hline Secondary & $53(13.3)$ & $54(1 \mathrm{I} .6)$ & $75(24.7)$ & $53(14.1)$ & $3(0.5)$ \\
\hline High school & $37.5(10.7)$ & $52(3.5)$ & $47.5(22.0)$ & $57.5(9.5)$ & $3(0.8)$ \\
\hline University & 77 (I8.5) & $79(24.2)$ & $67(28.9)$ & $58(9.2)$ & $4.5(0.6)$ \\
\hline \multicolumn{6}{|c|}{ Absolute CD4 count in cells $/ \mathrm{mm}^{3}$} \\
\hline$<200$ & $59.5(8.7)$ & $52(14.0)$ & $66.5(17.5)$ & $59.5(10.6)$ & $3.5(1.2)$ \\
\hline $200-500$ & $56.5(16.3)$ & $56(13.1)$ & $57(19.9)$ & $56(8.0)$ & $4(0.6)$ \\
\hline$>500$ & $68(17.6)$ & $58(4.0)$ & $58(1 \mathrm{I} .4)$ & $63(2.1)$ & $4(0)$ \\
\hline
\end{tabular}

Abbreviations: HIV/AIDS, human immunodeficiency virus/acquired immune deficiency disorder; SD, standard deviation; WHO QOL-BREF, World Health Organization Quality of life questionnaire. 
social support did not significantly impact QOL scores in any domain.

\section{Discussion}

The results of the present study showed that the majority of the patients were adults afflicted with the disease at a young age. The mean age of the study participants was 38 years. Other studies have reported the mean age ranging from 33 to 36 years. ${ }^{5,8,15}$ The majority of the study participants were males, similar to the findings reported by Yadav. ${ }^{2}$ The majority of the study participants were unemployed which is in line with a similar study in Iran. ${ }^{15}$ Chronic ill health due to HIV/ AIDS makes affected individuals unlikely to be employed and is in agreement to our findings. ${ }^{27}$ Most of the participants had moderately low CD4 counts (200-500 cells $\left./ \mathrm{mm}^{3}\right)$. This should be expected in patients who are on regular follow-up for HAART.

In our study the median score was highest for physical domain among the four domains of QOL. This might be due to the fact that majority $(>70 \%)$ of the participants had a CD4 count more than 200 and were still physically capable of performing their daily activities. CD4 counts correlate well with clinical severity and hence determine physical agility. ${ }^{28}$

The psychological domain scored the lowest among the four categories. A similar finding was reported by Nojomi et al in Iran. ${ }^{15}$ A low score in the psychological domain in this study may be explained by the increased morbidity, negative feelings, and low self-esteem due to the perception of acquiring incurable disease. Rejection, isolation, avoidance, and denial are common manifestations among HIV/ AIDS patients in Nepal. ${ }^{29}$ This emphasizes the need for psychotherapy as an adjunct to the treatment of HIV/AIDS, besides the standard ART therapy.

Older age ( $>35$ years) was generally associated with higher QOL scores than those of their younger counterparts. However, it was statistically significant only in terms of the overall perception of QOL and not for all individual domains. There is some evidence that a younger age is associated with a better QOL in HIV/AIDS. ${ }^{11}$ Sex had a significant influence on the QOL scores in the social and psychological domain. This explains that women are stigmatized more than men for having HIV/AIDS, lack family support, and are considered as a passive partner from social and economic point of view. Previous studies have shown that women with HIV/AIDS report poorer QOL than men. ${ }^{8-10}$ Men and women are often not dealt with in the same way when infected or believed to be infected by HIV: a woman is more likely to be blamed even when the source of her infection is her husband, and infected women may be less likely to be accepted by their communities. ${ }^{30}$

The clinical category and the marital status of a patient (married versus single/widowed/separated) seemed to significantly influence the QOL scores in the environmental domain. The environmental domain assesses the influence of factors like financial resources, work environment, accessibility to health and social care, freedom, security, participation, and opportunities for leisure activities on the QOL. Previous studies have shown that CD4 count has a significant impact on QOL scores in HIV/AIDS patients. ${ }^{8,11-13}$ Patients with clinically advanced disease are less likely to engage in the environment around them including participating in leisure activities leading to poor self-esteem and personal satisfaction. A spouse is often a source of major support, in terms of finances, safety, and security. A good and supportive home environment can help the patient feel better. This accounts for higher environmental domain scores seen in married individuals and has been shown before. ${ }^{15}$

Although the median scores indicated that higher education was related to better QOL scores, the difference was not statistically significant. Although contrary to previous evidence, ${ }^{15,17,18}$ it could be possible that this group of patients have received proper education and counseling from health care and support organizations regarding HIV infection, healthy lifestyle, HAART, and safe sex behavior nullifying the impact of one's educational status. Similarly, employment status and perceived social support seemed to have no impact on QOL scores in the study. We do not have a satisfactory explanation for these findings. It is likely that our patients were receiving some form of financial help from social service organizations (which was not analyzed in the study) and thus, being unemployed, did not affect their financial capability.

A multiple linear regression analysis could not be performed in the study because of the low sample size as well as because a satisfactory linear relationship could not be established between many of the variables and the QOL scores.

One major limitation of this study was its small sample size. We did not investigate the impact of institutional support from social service organizations on the QOL of HIV/AIDS patients. QOL was self-reported; hence, some reporting bias of close personal issues in the questionnaire is expected. In case of illiterate study participants, questionnaires were completed with the aid of study investigators. We cannot completely rule out some reporting bias and miscommunication in such situations. We did not have a control group to make suitable comparisons. In the absence of a multivariate analysis, the 
results of the bivariate analysis should be considered with caution.

\section{Conclusion}

Being older, female, and single with a lower CD4 count is associated with poorer QOL in people living with HIV/ AIDS in Nepal. HAART alone may not necessarily improve quality of life in this group. Lowest QOL scores were seen in the psychological domain, suggesting that psychological interventions are required in this population. Further welldesigned qualitative and quantitative studies need to be done to find out the real status of QOL in this population.

\section{Acknowledgments}

The authors would like to thank staff members of the ART clinic, Tribhuvan University Teaching Hospital, and the patients who cooperated during the study. The authors also acknowledge the help of Sudha Regmi and Leigh Anne Eller in editing the manuscript.

\section{Disclosure}

The authors report no conflicts of interest in this work.

\section{References}

1. UNAIDS. Global AIDS Epidemic Facts and Figures. 2012; http://www. unaids.org/en/dataanalysis/knowyourepidemic/. Accessed August 3, 2013.

2. Yadav S. Perceived social support, hope, and quality of life of persons living with HIV/AIDS: a case study from Nepal. Qual Life Res. 2010;19(2):157-166.

3. NCASC. HIV Epidemic Update of Nepal. 2012; http://www.ncasc.gov. np/uploaded/facts_n_figure/FactSheet_2012/Factsheet\%201_HIV_ epidemic_update_Nov_25_2012.pdf. Accessed August 3, 2013.

4. Porter K, Babiker A, Bhaskaran K, et al; CASCADE Collaboration. Determinants of survival following HIV-1 seroconversion after the introduction of HAART. Lancet. 2003;362(9392):1267-1274.

5. Wig N, Lekshmi R, Pal H, Ahuja V, Mittal CM, Agarwal SK. The impact of HIV/AIDS on the quality of life: a cross sectional study in north India. Indian J Med Sci. 2006;60(1):3-12.

6. Tiwari MK, Verma S, Agrawal D, Agrawal H. Quality of life of patients with HIV infection. Indian J Soc Sci Res. 2009;6(2):8.

7. Friedland J, Renwick R, McColl M. Coping and social support as determinants of quality of life in HIV/AIDS. AIDS Care. 1996;8(1):15-31.

8. Nirmal B, Divya KR, Dorairaj VS, Venkateswaran K. Quality of life in HIV/AIDS patients: a cross-sectional study in south India. Indian $J$ Sex Transm Dis. 2008;29(1):3.

9. Mrus JM, Williams PL, Tsevat J, Cohn SE, Wu AW. Gender differences in health-related quality of life in patients with HIV/AIDS. Qual Life Res. 2005;14(2):479-491.
10. Cederfjäll C, Langius-Eklöf A, Lidman K, Wredling R. Gender differences in perceived health-related quality of life among patients with HIV infection. AIDS Patient Care STDS. 2001;15(1):31-39.

11. Ruiz Perez I, Rodriguez Baño J, Lopez Ruz MA, et al. Health-related quality of life of patients with HIV: impact of sociodemographic, clinical and psychosocial factors. Qual Life Res. 2005;14(5):1301-1310.

12. Ruiz-Pérez I, Olry de Labry-Lima A, López-Ruz MA, et al. Clinical status, adherence to HAART and quality of life in HIV-infected patients receiving antiretroviral treatment. Enferm Infecc Microbiol Clin. 2005;23(10):581-585. Spanish.

13. Swindells S, Mohr J, Justis JC, et al. Quality of life in patients with human immunodeficiency virus infection: impact of social support, coping style and hopelessness. Int J STD AIDS. 1999;10(6):383-391.

14. Bello SI, Bello IK. Quality of life of HIV/AIDS patients in a secondary health care facility, Ilorin, Nigeria. Proc (Bayl Univ Med Cent). 2013;26(2):116-119.

15. Nojomi M, Anbary K, Ranjbar M. Health-related quality of life in patients with HIV/AIDS. Arch Iran Med. 2008;11(6):608-612.

16. da Silva J, Bunn K, Bertoni RF, Neves OA, Traebert J. Quality of life of people living with HIV. AIDS Care. 2013;25(1):71-76.

17. Santos EC, França I, Lopes F. Quality of life of people living with HIV/ AIDS in São Paulo, Brazil. Rev Saude Publica. 2007;41 Suppl 2:64-71. Portuguese.

18. Eriksson LE, Nordström G, Berglund T, Sandström E. The healthrelated quality of life in a Swedish sample of HIV-infected persons. J Adv Nurs. 2000;32(5):1213-1223.

19. Eller LS, Mahat G. Predictors of life satisfaction in HIV-positive Nepali women. J Assoc Nurses AIDS Care. 2007;18(5):17-26.

20. Saxena S, Carlson D, Billington R; WHOQOL Group. World Health Organisation Quality Of Life. The WHO quality of life assessment instrument (WHOQOL-Bref): the importance of its items for crosscultural research. Qual Life Res. 2001;10(8):711-721.

21. Fang CT, Hsiung PC, Yu CF, Chen MY, Wang JD. Validation of the World Health Organization quality of life instrument in patients with HIV infection. Qual Life Res. 2002;11(8):753-762.

22. Hsiung PC, Fang CT, Wu CH, et al. Validation of the WHOQOL-HIV BREF among HIV-infected patients in Taiwan. AIDS Care. 2011;23(8): $1035-1042$.

23. Sakthong P, Schommer JC, Gross CR, Sakulbumrungsil R, Prasithsirikul W. Psychometric properties of WHOQOL-BREF-THAI in patients with HIV/AIDS. J Med Assoc Thai. 2007;90(11):2449-2460.

24. Handajani YS, Djoerban Z, Irawan H. Quality of life people living with HIV/AIDS: outpatient in Kramat 128 Hospital Jakarta. Acta Med Indones. 2012;44(4):310-316.

25. Yu DS, Lee DT, Woo J. Issues and challenges of instrument translation. West J Nurs Res. 2004;26(3):307-320.

26. Bland JM, Altman DG. Cronbach's alpha. BMJ. 1997;314(7080):572.

27. Vitry-Henry L, Pénalba C, Béguinot I, Deschamps F. Relationships between work and HIV/AIDS status. Occup Med (Lond). 1999;49(2):115-116.

28. Korenromp EL, Williams BG, Schmid GP, Dye C. Clinical prognostic value of RNA viral load and CD4 cell counts during untreated HIV-1 infection - a quantitative review. PLoS One. 2009;4(6):e5950.

29. Rai B. HIV and AIDS: Related Stigma and Discrimination in Nepal. Amsterdam: Vrije Universiteit Amsterdam; 2008.

30. UNAIDS. HIV-Related Stigma, Discrimination and Human Rights Violations: Case Studies of Successful Programmes. Geneva: UNAIDS; 2005.

\section{Dovepress}

\section{Publish your work in this journal}

HIV/AIDS - Research and Palliative Care is an international, peerreviewed open-access journal focusing on advances in research in HIV, its clinical progression and management options including antiviral treatment, palliative care and public healthcare policies to control viral spread. The journal welcomes original research, basic science,

Submit your manuscript here: http://www.dovepress.com/hivaids---research-and-palliative-care-journal clinical \& epidemiological studies, reviews \& evaluations, expert opinion \& commentary, case reports \& extended reports. The manuscript management system is completely online and includes a very quick and fair peer-review system. Visit http://www.dovepress.com/ testimonials.php to read real quotes from published authors. 